\title{
The relation of proinsulin and insulin to insulin sensitivity and acute insulin response in subjects with newly diagnosed Type II diabetes: the Insulin Resistance Atherosclerosis Study
}

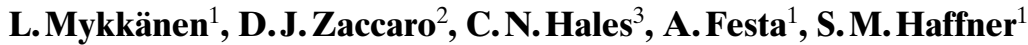 \\ ${ }^{1}$ Division of Clinical Epidemiology, Department of Medicine, University of Texas Health Science Center at San Antonio, \\ San Antonio, USA \\ ${ }^{2}$ Department of Public Health Sciences, Wake Forest University, School of Medicine, Winston-Salem, North Carolina, USA \\ ${ }^{3}$ Department of Clinical Biochemistry, University of Cambridge, Cambridge, UK
}

\section{Abstract}

Aims/hypothesis. Proinsulin concentrations are increased relative to insulin concentrations in subjects with Type II (non-insulin-dependent) diabetes mellitus. This could be secondary to hyperglycaemia or insulin resistance or due to a defect in insulin secretion. Methods. We investigated the association between fasting insulin, intact proinsulin and the intact proinsulin: insulin ratio with insulin sensitivity, estimated by a frequently sampled intravenous glucose tolerance test and the minimal model and with acute insulin response (AIR) in 182 newly diagnosed Type II diabetic subjects aged 40 to 69 years. None of the subjects was receiving hypoglycaemic medication.

Results. Insulin sensitivity correlated inversely with fasting insulin $\left(r_{\mathrm{s}}=-0.42\right)$ and intact proinsulin $\left(r_{\mathrm{s}}=-0.32\right)(p<0.001)$. The intact proinsulin:insulin ratio was not correlated with insulin sensitivity. AIR correlated positively with intact proinsulin $\left(r_{\mathrm{s}}=0.23\right)$ and inversely with the intact proinsulin:insulin ratio $\left(r_{\mathrm{s}}=-0.29, p<0.001\right)$. Fasting glucose correlated positively with intact proinsulin $\left(r_{\mathrm{s}}=0.34\right)$ and the intact proinsulin:insulin ratio $\left(r_{\mathrm{s}}=0.24, p<0.001\right)$. The intact proinsulin:insulin ratio increased by decreasing AIR (quartiles of AIR from high to low: 7.8, 8.2, 9.7 and $12.1 \%, p<0.001)$. This association was independent of age, sex, ethnicity, body mass index, fasting glucose, and insulin sensitivity.

Conclusion/interpretation. Insulin resistance (low insulin sensitivity) was not related to the intact proinsulin:insulin ratio in subjects with Type II diabetes. In contrast, both low AIR and high fasting glucose concentrations were associated with a disproportionate increase in proinsulin concentration. These results suggest that increased intact proinsulin:insulin ratio is a marker of a defect in insulin secretion in Type II diabetic subjects. [Diabetologia (1999) 42: 10601066]

Keywords Proinsulin, insulin, insulin secretion, insulin resistance.
Simultaneously with insulin and C peptide, beta cells also secrete a small amount of proinsulin and its conversion intermediates [1]. Insulin and proinsulin

Received: 25 February 1999 and in revised form: 12 April 1999

Corresponding author: L. Mykkänen, $\mathrm{MD}, \mathrm{PhD}$, Division of Clinical Epidemiology, Department of Medicine, University of Texas Health Science Center at San Antonio, 7703 Floyd Curl Drive, San Antonio, TX 78284-7873, USA

Abbreviations: AIR, acute insulin response; IRAS, Insulin Resistance Atherosclerosis Study; $\sigma$ intraclass correlation coefficient; $r_{\mathrm{s}}$ Spearman's correlation coefficient; $r^{2}$ coefficient of determination; $S_{\mathrm{I}}$ insulin sensitivity. cross-react in conventional insulin radioimmunoassays. Plasma proinsulin concentrations are considerably increased in patients with Type II (non-insulindependent) diabetes mellitus and constitute a substantial proportion of the total insulin-containing molecules [2-7]. Also subjects with impaired glucose tolerance (IGT) have higher proinsulin concentrations than normoglycaemic subjects [4-6, 8, 9]. Furthermore, high fasting proinsulin concentrations or proinsulin:insulin ratios have been shown to be associated with the development of Type II diabetes within 2-5 years [10-12].

The reasons for hyperproinsulinaemia are largely unknown. In subjects with IGT and overt Type II dia- 
betes, hyperproinsulinaemia could be secondary to hyperglycaemia [13]. Additionally, increased insulin demand caused by insulin resistance could induce the beta cell to increase secretion of proinsulin more than insulin. Three observational studies have previously investigated the relation between proinsulin concentration and insulin resistance [14-16]. In these studies, fasting insulin, intact proinsulin, and 32, 33 split proinsulin concentrations were inversely associated with insulin sensitivity in normoglycaemic subjects. In one study insulin resistance was, however, associated with a low rather than high proinsulin:insulin ratio [15] and in another study the proinsulin:insulin ratio was not related to insulin resistance [16]. In the third study [14], the proinsulin:insulin ratio was not assessed. These results indicated that in subjects with normal glucose tolerance, insulin resistance does not induce increased proinsulin relative to insulin secretion. No study has examined the proinsulin:insulin ratio in relation to the degree of insulin resistance in Type II diabetic patients. Finally, hyperproinsulinaemia might be related to an intrinsic beta-cell defect in Type II diabetic patients, as has been suggested [17]. Nevertheless, data on the relation between insulin secretion and the proinsulin:insulin ratio in diabetic patients are scarce. Recently, the fasting proinsulin:insulin ratio was found to be a marker of the degree of reduced maximum beta-cell secretory capacity in nine subjects with Type II diabetes [18]. The majority of the subjects in that study were treated with sulphonylureas, which probably had an effect on their insulin secretion capacity [18].

This study was undertaken to examine the association between fasting intact proinsulin, 32, 33 split proinsulin and the proinsulin:insulin ratios, and insulin sensitivity and acute insulin response in a large number of newly diagnosed Type II diabetic subjects $(n=182]$ who participated in the Insulin Resistance Atherosclerosis Study. We investigated these relations in newly diagnosed Type II diabetic subjects because they were not receiving hypoglycaemic medication which affects both insulin secretion and insulin sensitivity.

\section{Subjects and methods}

The Insulin Resistance Atherosclerosis Study (IRAS) is a multicentre epidemiological study on insulin resistance, cardiovascular risk factors and disease in African Americans, Hispanics, and non-Hispanic whites across a broad range of glucose tolerance. A full description of the design and methods of the IRAS has been published [19]. In brief, this study was conducted at four clinical centres. Clinical centres in Oakland and Los Angeles, California, studied non-Hispanic whites and African Americans recruited from Kaiser Permanente, a nonprofit health maintenance organization. Clinical centres in San Antonio, Texas, and San Luis Valley, Colorado, studied non-Hispanic whites and Hispanics recruited from two ongoing popu- lation-based studies (the San Antonio Heart Study [20] and the San Luis Valley Diabetes Study [21]). Recruitment was tailored to yield approximately equal numbers of participants by ethnicity, sex, and glucose tolerance categories [Type II diabetes, impaired glucose tolerance (IGT) and normal glucose tolerance].

The final study sample constituted 613 non-Hispanic whites, 548 Hispanics and 464 African Americans [19]. Participants with normal glucose tolerance constituted the largest segment of the study sample (44\%), followed by diabetic subjects $(33 \%)$ and people with IGT $(23 \%)$. A total of 537 subjects with Type II diabetes participated in the IRAS. Of them, 182 subjects were first diagnosed as having diabetes at the study visit and had data on insulin sensitivity $\left(S_{\mathrm{I}}\right)$, acute insulin response (AIR) and proinsulin concentration, and they constitute the study population for this report.

The IRAS examination required two visits [ $\sim 1$ week apart (range, 2 to 28 days)], each lasting about $4 \mathrm{~h}$. Height and weight were measured in accordance with a standardized protocol. Body mass index [weight $(\mathrm{kg})$ divided by the height $\left(\mathrm{m}^{2}\right)$ ] was used as an estimate of overall adiposity. Participants were asked before each visit to fast for $12 \mathrm{~h}$, to abstain from vigorous exercise and alcohol for $24 \mathrm{~h}$, and to refrain from smoking on the morning of the examination. For the oral glucose tolerance test, a 75-g glucose load (Orangedex, Customs Laboratories, Baltimore, Md., USA) was given over a period less than $10 \mathrm{~min}$. Blood was collected before ingestion and $2 \mathrm{~h}$ after the glucose load. Glucose tolerance status was based on the World Health Organization criteria [22].

Insulin sensitivity was assessed by a frequently sampled intravenous glucose tolerance test (FSIGT) [23] with minimal model analyses [24]. Two modifications of the original protocol were used. An injection of regular insulin, rather than tolbutamide, was used to ensure adequate plasma insulin concentrations for the accurate computation of insulin sensitivity across a broad range of glucose tolerance [25]. This was because of the blunted insulin response in diabetic subjects. In addition, the reduced sampling protocol (which required 12 rather than 30 plasma samples and shows results similar to the full protocol [26]) was used because of the large number of subjects. Glucose in the form of a $50 \%$ solution $(0.3 \mathrm{~g} / \mathrm{kg})$ and regular human insulin $(0.03 \mathrm{U} / \mathrm{kg})$ were injected through an intravenous line at 0 and $20 \mathrm{~min}$, respectively. Blood was collected at $-5,2$, $4,8,19,22,30,40,50,70,100$, and $180 \mathrm{~min}$ for plasma glucose and insulin concentrations. Insulin sensitivity, expressed as the insulin sensitivity index $\left(S_{\mathrm{I}}\right)$, was calculated by mathematical modelling methods (MINMOD, version 3.0 [1994]). Acute insulin response (AIR) was calculated as the mean of insulin concentrations at 2 and 4 min after glucose injection.

Plasma glucose was measured with the glucose oxidase technique on an automated autoanalyser (Yellow Springs, Ohio, USA). Insulin was measured using the dextran-charcoal radioimmunoassay [27] which has considerable cross-reactivity with human proinsulin. From 163 blind duplicate fasting specimens, the external coefficient of variation for plasma insulin measurements was $19 \%$. Glucose and insulin were measured at the central IRAS laboratory at the University of Southern California, Los Angeles, USA.

Fasting intact proinsulin and 32, 33 split proinsulin were determined by highly specific two-site monoclonal antibodybased immunoradiometric assays, with an interassay coefficient of variation of less than $10 \%$ [28]. There was no detectable cross-reactivity of insulin or 32,33 split proinsulin in the intact proinsulin assay. Insulin did not statistically significantly cross-react in the assay for 32, 33 split proinsulin; the cross-reactivity for intact proinsulin in this assay was $84 \%$. Assay values of 32, 33 split proinsulin were corrected for by subtracting 
Table 1. Characteristics of the study cohort $(n=182)$

\begin{tabular}{|c|c|}
\hline \multicolumn{2}{|l|}{ Demographic } \\
\hline Age (years) & $57.7 \pm 8.1$ \\
\hline Men (\%) & $41.8(76)$ \\
\hline \multicolumn{2}{|l|}{ Ethnicity } \\
\hline$\%$ African American & $36.8(67)$ \\
\hline \% Hispanic & $29.1(53)$ \\
\hline$\%$ Non-Hispanic white & $34.1(62)$ \\
\hline \multicolumn{2}{|l|}{ Obesity } \\
\hline $\mathrm{BMI}\left(\mathrm{kg} / \mathrm{m}^{2}\right)$ & $31.9 \pm 5.7$ \\
\hline \multicolumn{2}{|l|}{ Glucose } \\
\hline Fasting glucose (mmol/l) & $7.9 \pm 2.3$ \\
\hline 2-h glucose $(\mathrm{mmol} / \mathrm{l})$ & $14.8 \pm 3.3$ \\
\hline \multicolumn{2}{|l|}{ Insulin and proinsulin } \\
\hline Fasting insulin (pmol/l) & $132(90-192)$ \\
\hline 2-h insulin $(\mathrm{pmol} / \mathrm{l})$ & $717(429-1074)$ \\
\hline Intact proinsulin $(\mathrm{pmol} / \mathrm{l})^{\mathrm{a}}$ & $12(7.4-18.0)$ \\
\hline 32,33 split proinsulin $(\mathrm{pmol} / \mathrm{l})^{\mathrm{a}}$ & $17(9.8-28)$ \\
\hline Intact proinsulin : insulin ratio $(\%)^{\mathrm{a}}$ & $8.9(5.9-14)$ \\
\hline Split proinsulin : insulin ratio $(\%)^{\mathrm{a}}$ & $13.3(9.1-19)$ \\
\hline$S_{\mathrm{I}} \times 10^{-4}\left(\mathrm{~min}^{-1} \cdot \mu \mathrm{U}^{-1} \cdot \mathrm{ml}^{-1}\right)$ & $0.37(0.00-0.80)$ \\
\hline AIR (pmol/l) & $144(93-243)$ \\
\hline
\end{tabular}

Data are means $\pm \mathrm{SD}, \%(n)$ or median (interquartile range).

${ }^{\mathrm{a}}$ Fasting concentrations

the corresponding intact proinsulin cross-reactivity. The assay of 32,33 split proinsulin cross-reacts equally with 32,33 , des 32 and des 31,32 split proinsulins. We used the term 32,33 split proinsulin to indicate the sum of these three molecules, the majority of which are des 31, 32 split proinsulin [29]. The sensitivity limit of the intact proinsulin and 32,33 split proinsulin assays was $1.25 \mathrm{pmol} / \mathrm{l}$ ( 3 SDs from zero). From 98 blind duplicate specimens, the external coefficient of variation for intact proinsulin measurements was $14 \%$ and for 32,33 split proinsulin measurements was $18 \%$. Intact proinsulin and 32,33 split proinsulin were determined at the laboratory of the Department of Clinical Biochemistry at Addenbrook's Hospital, Cambridge, United Kingdom.

An informed consent was obtained from the subjects and the study protocol was approved by institutional review boards in all participating centres.

Statistical methods. The study cohort was described with means \pm SD or medians (interquartile range) for demographic and clinical variables (Table 1). Spearman correlation coefficients were computed on untransformed data to describe the association between insulin and proinsulin variables and predictor variables (Table 2). The insulin, proinsulin, and proinsulin:insulin ratios and insulin sensitivity variables were all log transformed for multiple regression models to satisfy statistical assumptions. After the log transformation, all these variables were normally distributed. Multiple linear regression models were used to assess the impact of AIR (as quartiles) and $S_{\text {I }}$ (as quartiles) on insulin and proinsulin variables while adjusting for potentially confounding variables (Tables 3 and 4). Three successive regression models were fit for each dependent variable: model 1) adjusted for age, sex, ethnicity, and clinic; model 2) model 1 plus BMI; model 3) model 2 plus fasting glucose. An additional model which added insulin sensitivity $\left(S_{\mathrm{I}}\right)$ to model 3 was fit for the models which examined the impact of AIR on dependent variables. Adjusted means (SEM) for dependent variables were computed and were back transformed into the original units. We calculated values for trends in the differences in insulin and proinsulin variables from linear con-
Table 2. Spearman correlations among fasting insulin and proinsulin concentrations and insulin sensitivity, acute insulin response, body mass index and fasting glucose concentration

\begin{tabular}{lcccc}
\hline & \multicolumn{1}{l}{$S_{\text {I }}$} & AIR & BMI & $\begin{array}{c}\text { Fasting } \\
\text { glucose }\end{array}$ \\
\hline Fasting insulin & $-0.42^{\mathrm{c}}$ & - & $0.52^{\mathrm{c}}$ & $0.17^{\mathrm{a}}$ \\
Intact proinsulin & $-0.32^{\mathrm{c}}$ & $0.23^{\mathrm{b}}$ & $0.49^{\mathrm{c}}$ & $0.34^{\mathrm{c}}$ \\
32, 33 split proinsulin & $-0.38^{\mathrm{c}}$ & $0.42^{\mathrm{c}}$ & $0.53^{\mathrm{c}}$ & $0.28^{\mathrm{c}}$ \\
$\begin{array}{l}\text { Intact proinsulin : } \\
\text { insulin ratio }\end{array}$ & 0.06 & $-0.29^{\mathrm{c}}$ & 0.05 & $0.24^{\mathrm{c}}$ \\
Split proinsulin : & & & & \\
insulin ratio & -0.09 & -0.02 & $0.18^{\mathrm{a}}$ & $0.23^{\mathrm{b}}$ \\
BMI & $-0.26^{\mathrm{c}}$ & $0.22^{\mathrm{b}}$ & - & $0.26^{\mathrm{c}}$ \\
Fasting glucose & -0.08 & $-0.35^{\mathrm{c}}$ & $0.26^{\mathrm{c}}$ & - \\
$S_{\mathrm{I}}$ & - & $-0.32^{\mathrm{c}}$ & $-0.26^{\mathrm{c}}$ & -0.08 \\
AIR & $-0.32^{\mathrm{c}}$ & - & $0.22^{\mathrm{b}}$ & $-0.35^{\mathrm{c}}$ \\
\hline
\end{tabular}

${ }^{\mathrm{a}} p<0.05,{ }^{\mathrm{b}} p<0.01,{ }^{\mathrm{c}} p<0.001$

trasts of the four means (from each AIR or $S_{\text {I }}$ quartile) calculated from the regression models. Multiple linear regression analysis was also used to investigate independent relations of AIR, $S_{\mathrm{I}}$, fasting glucose, and BMI as continuous variables with proinsulin:insulin ratio (Table 5). All multiple regression models were fit using the PROC GLM component of the SAS system (Cary, N. C., USA).

\section{Results}

Characteristics of the study cohort are shown in Table 1 . The mean age was 57.7 years and $41.8 \%$ of the subjects were men. None of the subjects were receiving hypoglycaemic medication. The median $S_{\mathrm{I}}$ was $0.37 \times 10^{-4} \mathrm{~min}^{-1} \cdot \mu \mathrm{U}^{-1} \cdot \mathrm{ml}^{-1}$ and the median AIR was $144 \mathrm{pmol} / \mathrm{l}$.

Table 2 shows results of Spearman correlation analyses. Fasting insulin concentration correlated inversely with $S_{\mathrm{I}}$ and positively with BMI. Also concentrations of intact and 32,33 split proinsulin correlated inversely with $S_{\text {I }}$ and positively with AIR and BMI. Proinsulins correlated positively with the fasting glucose concentration. Intact proinsulin:insulin ratio did not correlate with $S_{\mathrm{I}}$. In contrast, intact proinsulin:insulin ratio correlated inversely with AIR. The split proinsulin:insulin ratio was not associated with $S_{\mathrm{I}}$ or with AIR. Proinsulin-to-insulin ratios correlated positively with the fasting glucose concentration. There was an inverse relation between $S_{\text {I }}$ and AIR. Among the insulin and proinsulin variables, 32,33 split proinsulin had the strongest correlations with AIR; its correlation coefficient was 1.5 times larger than the correlation coefficient for the intact proinsulin:insulin ratio. The intact proinsulin:insulin ratio was, however the only insulin variable which correlated specifically with AIR; all other insulin and proinsulin variables correlated similarly with AIR and $S_{\mathrm{I}}$. 
Table 3. Relation of fasting insulin and proinsulin concentrations and proinsulin : insulin ratios to $S_{\text {I }}$

\begin{tabular}{|c|c|c|c|c|c|c|c|}
\hline & \multicolumn{4}{|c|}{ Quartiles of $S_{\mathrm{I}}$} & \multicolumn{3}{|c|}{ Test for trend } \\
\hline & I (low) & II & III & IV (high) & $p$ value $^{\mathrm{a}}$ & $p$ value $^{\mathrm{b}}$ & $p$ value $^{\mathrm{c}}$ \\
\hline Fasting insulin (pmol/l) & $156(17)$ & $124(15)$ & $117(13)$ & $84(1)$ & $<0.001$ & $<0.001$ & $<0.001$ \\
\hline Intact proinsulin : insulin ratio (\%) & $8.3(0.9)$ & $11.8(1.7)$ & $9.3(1.2)$ & $9.1(1.2)$ & 0.963 & 0.673 & 0.605 \\
\hline Split proinsulin : insulin ratio (\%) & $13.2(1.3)$ & $16.4(2.3)$ & $13.1(1.5)$ & $11.6(1.4)$ & 0.130 & 0.471 & 0.505 \\
\hline
\end{tabular}

Data are means adjusted for age, sex, ethnicity and clinic a Test for trend using linear contrasts after adjusting for age, (SEM).

Quartiles of $S_{\mathrm{I}} \times 10^{-1}\left(\mathrm{~min}^{-1} \cdot \mu \mathrm{U}^{-1} \cdot \mathrm{ml}^{-1}\right)$ were as follows: I quartile $S_{\text {I }}=0 ; \quad$ II quartile $0.03 \leq S_{\text {I }} \leq 0.43$; III quartile sex, ethnicity and clinic; ${ }^{b}$ test for trend using linear contrasts after adjusting for age, sex, ethnicity, clinic and BMI; ${ }^{\mathrm{c}}$ test for trend using linear contrasts after adjusting for age, sex, ethnicity, clinic, BMI and fasting glucose

Table 4. Relation of fasting insulin and proinsulin concentrations and proinsulin : insulin ratios to AIR

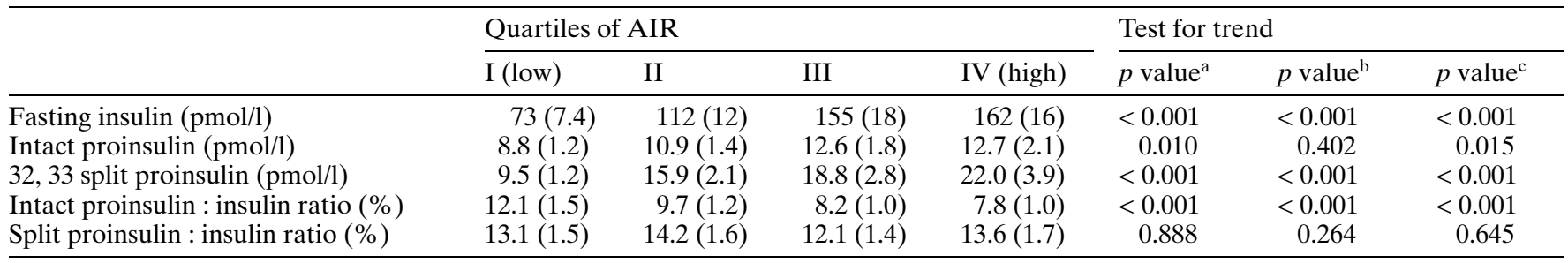

Data are means adjusted for age, sex, ethnicity and clinic (SEM).

Quartiles of AIR (pmol/l) were as follows: I quartile AIR $\leq 93$; II quartile $93<$ AIR $\leq 144 ;$ III quartile $144<$ AIR $<243$; IV quartile AIR $\geq 243$.

Table 5. Multiple linear regression analysis with log (intact proinsulin : insulin ratio) as dependent variable

\begin{tabular}{lrrrl}
\hline $\begin{array}{l}\text { Independent } \\
\text { variable }\end{array}$ & $\mathrm{B}$ & $\mathrm{SE}(\mathrm{B})$ & $p$ value & Partial $r^{2}$ \\
\hline Log AIR & -0.1717 & 0.0794 & 0.032 & $2.4 \%$ \\
Fasting glucose & 0.0022 & 0.0013 & 0.076 & $1.7 \%$ \\
$\mathrm{BMI}$ & 0.0152 & 0.0091 & 0.095 & $1.5 \%$ \\
Log $S_{\mathrm{I}}$ & 0.0830 & 0.1389 & 0.550 & $0.2 \%$ \\
$\mathrm{R}^{2}$ for the model $=8.3 \%$ & & & \\
\hline
\end{tabular}

Before $\log$ transformation 1 was added to $S_{\text {I values }}$

We also did Spearman correlation analyses separately in each ethnic group. Correlations between intact proinsulin:insulin ratio and $S_{\mathrm{I}}$ were 0.08 $(p=\mathrm{NS}), 0.03(p=\mathrm{NS})$ and $0.11(p=\mathrm{NS})$ in African Americans, Hispanics and non-Hispanic whites, respectively. Correlations between the intact proinsulin:insulin ratio and AIR were $-0.25(p<0.05),-0.30$ $(p<0.05)$, and $-0.29(p<0.05)$ in African Americans, Hispanics, and non-Hispanic whites, respectively. Thus, the relation between the intact proinsulin:insulin ratio and AIR was consistently inverse in all ethnic groups, and insulin resistance was not related to disproportionate proinsulin concentrations in any of the three ethnic groups.

Table 3 shows fasting insulin and proinsulin concentrations and proinsulin:insulin ratios by quartiles
${ }^{a}$ Test for trend using linear contrasts after adjusting for age, sex, ethnicity and clinic; ${ }^{b}$ test for trend using linear contrasts after adjusting for age, sex, ethnicity, clinic and BMI; ${ }^{\mathrm{c}}$ test for trend using linear contrasts after adjusting for age, sex, ethnicity, clinic, BMI and fasting glucose

of $S_{\mathrm{I}}$. Fasting insulin, intact proinsulin, and split proinsulin concentrations decreased with increasing $S_{\mathrm{I}}$. In contrast, proinsulin:insulin ratios were not related to $S_{\text {I }}$. These associations were independent of age, sex, ethnicity, clinic, BMI and fasting glucose. This indicates that insulin resistance was related to parallel increases in fasting proinsulin and insulin concentrations.

Table 4 shows fasting insulin and proinsulin concentrations and proinsulin:insulin ratios according to quartiles of AIR. Fasting insulin, intact proinsulin and split proinsulin concentrations increased and the intact proinsulin:insulin ratio decreased with increasing AIR. In other words, subjects with low AIR had statistically significantly lower fasting insulin and proinsulin concentrations and higher intact proinsulin:insulin ratio than subjects with high AIR. There was no relation between split proinsulin:insulin ratio and AIR. These relations were independent of age, sex, ethnicity, clinic, BMI and fasting glucose.

Given the inverse relation between AIR and $S_{\mathrm{I}}$, we also investigated whether the association between intact proinsulin:insulin ratio and AIR was independent of $S_{\text {I }}$. After further adjustment for $S_{\text {I }}$, newly diagnosed diabetic subjects with low AIR continued to have higher intact proinsulin:insulin ratio than subjects with high AIR (mean intact proinsulin:insulin ratio by quartiles of AIR: 12.4, 9.8, 7.8, 8.1, $p=0.002$ ). 
Finally, we used a multivariate linear regression analysis to investigate independent associations of AIR, $S_{\mathrm{I}}$, fasting glucose and BMI with intact proinsulin:insulin ratio (Table 5). Only AIR was related to the intact proinsulin:insulin ratio independently of the other variables.

\section{Discussion}

The finding of this study is that a low AIR to i.v. glucose is related to an increased fasting intact proinsulin:insulin ratio in newly diagnosed Type II diabetic patients who were not receiving hypoglycaemic medication. More importantly, this association was found in all three ethnic groups and was independent of obesity, fasting glucose concentration, and insulin sensitivity. Our results are in accordance with a previous study showing that proinsulin:insulin ratio correlated inversely with the maximum beta-cell secretory capacity in nine Type II diabetic subjects, the majority of whom were treated with sulphonylureas [18]. These results indicate that a disproportionate increase in plasma proinsulin concentrations is a marker of a defect in insulin secretion.

The hypothesis that hyperproinsulinaemia is related to an intrinsic beta-cell defect in Type II diabetic subjects was based on indirect evidence from experimental and observational studies showing that neither hyperglycaemia nor increased beta-cell secretory demand was necessary for the disproportionate release of proinsulin [17]. The first evidence that low insulin secretion in itself is associated with disproportionate proinsulin concentrations in Type II diabetes has recently been provided [18]. In that study there were nine diabetic subjects who had had diabetes for $10.8 \pm 1.8$ years, seven of whom were being treated with sulphonylureas. The magnitude of the elevation in fasting proinsulin:insulin ratio was shown to be related to the reduction in maximum beta-cell secretory capacity [18]. The maximum beta-cell secretory capacity was quantified as insulin response to i.v. arginine at maximum glycaemic potentiation. Oral hypoglycaemic medication affects both insulin secretion and insulin sensitivity and therefore we decided to investigate the relation of proinsulin:insulin ratio with insulin secretion and sensitivity in newly diagnosed Type II diabetic subjects who were not receiving hypoglycaemic medication. Our findings confirm that a disproportionate increase in plasma proinsulin concentrations is indeed a marker of a defect in insulin secretion in Type II diabetic subjects. We did not measure the maximum beta-cell secretory capacity but acute insulin response to i.v. glucose. The cause of reduced acute insulin response to i.v. glucose in Type II diabetes is not known. Hyperglycaemia in itself may have affected both AIR and $S_{\text {I }}$. Our study cohort of 182 Type II diabetic subjects was substan- tially larger than in the previous study [18] and represented three ethnic groups, which makes our results more generalizable to other diabetic populations.

It is not clear why an increased intact proinsulin:insulin ratio was related to a low AIR but the split proinsulin:insulin ratio was not associated with AIR. Processing of proinsulin to split proinsulins and further to insulin in beta cells is catalysed by proprotein convertases PC3 (also known as PC1) and PC2 [13]. If low AIR was associated with an impairment in processing of intact proinsulin to 32,33 split proinsulin and des 31, 32 split proinsulin but with less impaired conversion of des 31,32 split proinsulin to insulin, this could lead to an increased intact proinsulin:insulin ratio while split proinsulin:insulin ratio might change little. Another possible explanation could be different precision of the intact and split proinsulin assays used in this study. The 32, 33 split proinsulin assay is less precise at low serum concentrations than the assay of intact proinsulin. This is due to the 32, 33 split proinsulin assay being inherently a little less sensitive than the assay of intact proinsulin and the need to subtract the intact proinsulin cross-reactivity which adds further potential error. This is, however, less of an issue in Type II diabetic subjects who have increased intact and split proinsulin concentrations. In our study we used an insulin assay which has considerable cross-reactivity with proinsulin, which adds error in estimating proinsulin:insulin ratios. It has, however, been shown that the cross-reactivity of a particular insulin assay with intact proinsulin and des 31,32 proinsulin are usually of the same magnitude although cross-reactivity of different insulin assays with proinsulin vary considerably [30].

Previous findings on the relation between proinsulin concentrations and insulin secretion in normoglycaemic subjects are contradictory. In one earlier study [14], fasting proinsulin and split proinsulin concentrations were not related to insulin secretion in normoglycaemic subjects. In contrast, we have reported previously that normoglycaemic subjects with a low acute insulin response to i.v. glucose had lower fasting specific insulin, intact proinsulin and 32, 33 split proinsulin concentrations and a higher intact proinsulin:insulin ratio than subjects with a high acute insulin response [15]. Furthermore, the association between acute insulin response and intact proinsulin:insulin ratio in these normoglycaemic subjects was independent of insulin resistance. The split proinsulin:insulin ratio was not related to AIR in the normoglycaemic subjects. Because the above study was a cross-sectional study, it is not known whether some of the normoglycaemic subjects with a low acute insulin response had decreased insulin secretion capacity and islet beta-cell dysfunction.

It has been suggested previously that the main cause of increases in the concentrations of insulin precursor molecules is hyperglycaemia coupled to 
relatively low activity of the endoprotease responsible for processing des 31, 32 split proinsulin to insulin [13]. Accordingly, in our study fasting intact proinsulin, 32, 33 split proinsulin, and proinsulin:insulin ratios were positively correlated with fasting glucose concentrations in newly diagnosed Type II diabetic patients. The strength of the correlation between intact proinsulin:insulin ratio and fasting glucose concentrations $\left(r_{\mathrm{s}}=0.24\right)$ was similar to the correlation between intact proinsulin:insulin ratio and AIR (-0.29). Furthermore, AIR was inversely correlated with fasting glucose concentration. These results support the idea that hyperglycaemia is an important determinant of the increased proinsulin:insulin ratio. Acute insulin response was, however, related to intact proinsulin:insulin ratio independently of the fasting glucose concentration, $S_{\mathrm{I}}$ and BMI. In contrast, the fasting glucose concentration was not associated with the intact proinsulin:insulin ratio independently of the other variables. It is possible that the relation between hyperglycaemia and intact proinsulin:insulin ratio would have been stronger, if we had used a marker of long-term glycaemic control, such as $\mathrm{HbA}_{1 \mathrm{C}}$ instead of the fasting glucose concentration but we did not measure $\mathrm{HbA}_{1 \mathrm{C}}$ values in this study.

Our results show that insulin resistance is not related to increased proinsulin:insulin ratios in Type II diabetic patients. Insulin resistance was associated with increased fasting intact and split proinsulin and insulin concentrations but the increase was similar for both proinsulin and insulin. This is in accordance with one previous study in normoglycaemic subjects [16]. It has, however, been reported that obese normoglycaemic Pima Indians, who were probably insulin resistant, had a lower proinsulin:insulin ratio than non-obese normoglycaemic Pimas [5]. In our previous study in normoglycaemic subjects [15], insulin resistance was associated with a low intact proinsulin:insulin ratio. This led us to hypothesize that in subjects with normal glucose tolerance, insulin resistance was associated with an enhanced processing of proinsulin [15]. If this is the case, the present study shows that enhanced processing of proinsulin associated with insulin resistance is blunted in Type II diabetic subjects. Thus, the existing data suggest that increased beta-cell secretory demand caused by insulin resistance does not result in excessive proinsulin secretion by diabetic islet beta cells nor by intact islet beta cells.

The lack of correlation between $S_{\mathrm{I}}$ and proinsulin:insulin ratios could be due to a higher variability of the $S_{\text {I }}$ measurement than the AIR measurement. We have done a study on repeatability of the $S_{\mathrm{I}}$ and AIR measurements in the IRAS [31]. Two intravenous glucose tolerance tests were done on 2 separate days about 2 weeks apart on the same participants, 23 of whom had Type II diabetes. The repeatability was assessed by calculating intraclass correlation co- efficient $(\sigma)$, which takes into account both variability among subjects and variability within a subject. In Type II diabetic subjects $\sigma=0.69$ for $S_{\text {I }}$ and $\sigma=0.77$ for AIR. These results show that the repeatability of the $S_{\text {I }}$ and AIR measurements was of the same magnitude in the IRAS. Therefore, we believe that the lack of correlation between $S_{\text {I }}$ and proinsulin:insulin ratios is a true finding.

In conclusion, in newly diagnosed Type II diabetes low insulin secretion was associated with a disproportionate increase in the intact proinsulin concentration in all three ethnic groups. This relation was independent of the fasting glucose concentration, insulin sensitivity and BMI. Insulin resistance was not related, however, to an increased intact proinsulin:insulin ratio. Our results support the hypothesis that an increased proinsulin:insulin ratio is a marker of a defect in insulin secretion [17].

\section{References}

1. Melani F, Rubenstein AH, Steiner DF (1970) Human serum proinsulin. J Clin Invest 49: 497-507

2. Ward WK, LaCava EC, Paquette TL, Beard JC, Wallum BJ, Porte D Jr (1987) Disproportionate elevation of immunoreactive proinsulin in Type II (non-insulin-dependent) diabetes mellitus and in experimental insulin resistance. Diabetologia 30: 698-702

3. Temple RC, Carrington CA, Luzio SD et al. (1989) Insulin deficiency in non-insulin-dependent diabetes. Lancet I: 293-295

4. Yoshioka N, Kuzuya T, Matsuda A, Taniguchi M, Iwamoto Y (1988) Serum proinsulin levels at fasting and after oral glucose load in patients with Type II (non-insulin-dependent) diabetes mellitus. Diabetologia 31: 355-360

5. Saad MF, Kahn SE, Nelson RG et al. (1990) Disproportionately elevated proinsulin in Pima Indians with noninsulin-dependent diabetes mellitus. J Clin Endocrinol Metab 70: $1247-1253$

6. Reaven GM, Chen Y-DI, Hollenbeck CB, Sheu WHH, Ostrega D, Polonsky KS (1993) Plasma insulin, C-peptide, and proinsulin concentrations in obese and nonobese individuals with varying degrees of glucose tolerance. J Clin Endocrinol Metab 76: 44-48

7. Birkeland KI, Torjesen PA, Erikson J, Vaaler S, Groop L (1994) Hyperproinsulinaemia of type II diabetes is not present before the development of hyperglycaemia. Diabetes Care 17: 1307-1310

8. Davies MJ, Rayman G, Gray IP, Day JL, Hales CN (1993) Insulin deficiency and increased plasma concentration of intact and 32/33 split proinsulin in subjects with impaired glucose tolerance. Diabet Med 10: 313-320

9. Haffner SM, Stern MP, Miettinen H, Gingerich R, Bowsher RR (1995) Higher proinsulin and specific insulin are both associated with a parental history of diabetes in nondiabetic Mexican-American subjects. Diabetes 44: 1156-1160

10. Kahn SE, Leonetti DL, Prigeon RL, Boyko EJ, Bergstrom RW, Fujimoto WY (1995) Proinsulin as a marker for the development of NIDDM in Japanese-American men. Diabetes 44: 173-179

11. Mykkänen L, Haffner SM, Kuusisto J, Pyörälä K, Hales CN, Laakso M (1995) Serum proinsulin levels are dispro- 
portionately increased in elderly prediabetic subjects. Diabetologia 38: 1176-1182

12. Nijjpels G, Popp-Snijders C, Kostense PJ, Bouter LM, Heine RJ (1996) Fasting proinsulin and 2-h post-load glucose levels predict the conversion to NIDDM in subjects with impaired glucose tolerance: the Hoorn Study. Diabetologia 39: 113-118

13. Hales CN, Byrne CD, Petry CJ, Wareham NJ (1996) Measurement of insulin and proinsulin. Diabetes Metab Rev 4: 320-335

14. Phillips DIW, Clark PM, Hales CN, Osmond C (1994) Understanding oral glucose tolerance: comparison of glucose or insulin measurements during the oral glucose tolerance test with specific measurements of insulin resistance and insulin secretion. Diabet Med 11: 286-292

15. Mykkänen L, Haffner SM, Hales CN, Rönnemaa T, Laakso M (1997) The relation of proinsulin, insulin, and proinsulin:insulin ratio to insulin sensitivity and acute insulin response in normoglycaemic subjects. Diabetes 46: 1990-1995

16. Wang PW, Abbasi F, Carontoni M, Chen Y-DI, Azhar S, Reaven GM (1997) Insulin resistance does not change the ratio of proinsulin to insulin in normal volunteers. J Clin Endocrinol Metab 82: 3221-3224

17. Porte D Jr, Kahn SE (1989) Hyperproinsulinaemia and amyloid in NIDDM: clues to etiology of islet $\beta$-cell dysfunction. Diabetes 38: 1333-1336

18. Røder ME, Porte D Jr, Schwartz RS, Kahn SE (1998) Disproportionately elevated proinsulin levels reflect the degree of impaired B cell secretory capacity in patients with noninsulin-dependent diabetes mellitus. J Clin Endocrinol Metab 83: 604-608

19. Wagenknecht LE, Mayer EJ, Rewers M et al. (1995) The Insulin Resistance Atherosclerosis Study (IRAS): objectives, design and recruitment results. Ann Epidemiol 5: 464-471

20. Stern MP, Rosenthal M, Haffner SM, Hazuda HP, Franco LJ (1984) Sex difference in the effects of sociocultural status on diabetes and cardiovascular risk factors in Mexican Americans: the San Antonio Heart Study. Am J Epidemiol 120: $834-851$
21. Hamman RF, Marshall JA, Baxter J et al. (1989) Methods and prevalence of non-insulin dependent diabetes mellitus in a biethnic Colorado population: the San Luis Valley Diabetes Study. Am J Epidemiol 129: 295-311

22. World Health Organization Study Group on Diabetes Mellitus (1985) Technical report series no. 727, WHO, Geneva

23. Bergman RN, Finegood DT, Ader M (1985) Assessment of insulin sensitivity in vivo. Endocrinol Rev 6: 45-86

24. Pacini G, Bergman RN (1986) MINMOD: a computer program to calculate insulin sensitivity and pancreatic responsivity from the frequently sampled intravenous glucose tolerance test. Comput Methods Programs Biomed 23: 113-122

25. Welch S, Gebhart SSP, Bergman RN, Phillips LS (1990) Minimal model analysis of intravenous glucose tolerance test derived insulin sensitivity in diabetic subjects. J Clin Endocrinol Metab 71: 1508-1518

26. Steil GM, Volund A, Kahn SE, Bergman RN (1993) Reduced sample number for calculation of insulin sensitivity and glucose effectiveness from the minimal model: suitability for use in population studies. Diabetes 42: 250-256

27. Herbert V, Lau K, Gottlieb C, Bleicher S (1965) Coated charcoal immunoassay of insulin. J Clin Endocrinol Metab 25: $1375-1384$

28. Sobey WJ, Beer SF, Carrington CA et al. (1989) Sensitive and specific two-site immunoradiometric assays for human insulin, proinsulin, 65,66 split and 32,33 split proinsulins. Biochem J 260: 535-541

29. Ostrega D, Polonsky K, Nagi D et al. (1995) Measurement of proinsulin and intermediates: validation of immunoassay methods by high-performance liquid chromatography. Diabetes 44: 437-440

30. Robbins DC, Andersen L, Bowsher R et al. (1996) Report of the American Diabetes Association's Task Force on Standardization of the Insulin Assay. Diabetes 45: 242-256

31. Zaccaro DJ, D'Agostino RB Jr, Karter A, Bergman R, Wagenknecht LE (1997) A comparison of the repeatability of insulin sensitivity with other cardiovascular disease risk factors. Can J Cardiol 13[Suppl B]: 197B (Abstract) 